\title{
THE DEVELOPMENT AND MAINTENANCE OF SUPERIOR GENETIC STOCKS *
}

\author{
O. H. FRANKEL
}

Wheat Reseorch Institute, Deportment of Scientific and Industrial Reseorch, Christchurch, New Zeolond

\section{THE COST-BENEFIT RATIO}

Received 19.v.49

THE increase in the world's resources of primary products which scientific plant breeding has brought about in scarcely more than a man's span of life cannot even approximately be estimated. It has raised the output of one crop or another in every part of the globe. There are instances of spectacular yield increases which have affected the food habits and improved the living standards of more than one continent. Hybrid maize, now almost universal in the United States, has raised yields by 25 per cent. over the varieties previously grown, adding some 700 million bushels a year to the world's grain resources. ${ }^{30}$ Improved varieties of wheat have increased the total wheat production in the U.S.A. by more than 800 million bushels in the years $1942-46 .^{3}$ In the prairie provinces of Western Canada the new stem-rust resistant wheats have produced an estimated annual yield increase of $4 \mathrm{I}$ million bushels valued at 27 million dollars. ${ }^{4}$

Modern varieties have raised the yield of winter wheat in Sweden by about 30 per cent. through combining high yielding capacity with winterhardiness, disease resistance and stiff straw. ${ }^{1}$

We must now consider the effort and expense involved in introducing techniques which have had such remarkable effects. Plant breeding is perhaps unique among resource techniques in requiring from the user little effort, in fact, as a rule, no change in management at all. The whole of the effort is confined to devising the new technique and this entails expenditure which, as a rule, is infinitesimal in comparison with the advances in productivity for which it is responsible. We have been instructed to place emphasis in our discussions on the " economic costs and benefits of the application of a given technique." We can say with conviction that the costbenefit ratio which plant breeding can claim will be hard to rival in any other branch of agricultural science. Plant breeding establishments are modest places with regard both to personnel and equipment; and once an improved variety is obtained, it goes on earning dividends, at best-as in self-fertilising and asexually propagated plants-at the modest cost of purification and certification,

* This paper has been presented to the United Nations Scientific Conference on the Conservation and Utilisation of Resources-U.N.S.C.C.U.R. It was written in the course of a visit to the John Innes Horticultural Institution, London. I am indebted to members of the staff for helpful criticisms. 
at worst-as in hybrid maize-at a cost which is small in proportion to the benefit it helps to spread. One may venture the generalisation that, so far, there probably has not been one plant breeding schemeprovided it was sensibly conducted-that has failed to pay a dividend. This is true not only for projects serving vast areas. In New Zealand the yield increase brought about by a new variety, which is grown in an isolated pocket of less than 3000 acres of wheat, repays the annual cost of all wheat breeding in that country.

But the cost-benefit ratio is not merely an absolute statistic; there is a relative component-as between plant breeding schemeswhich we must bear in mind particularly at this Conference. Yield increases may be obtained in a variety of ways, ${ }^{10}$ in the small-grained cereals, for example, by increasing the number of heads per plant, or the number of grains per head, or the weight of a single grain, or by a combination of any of these ; in short, by a direct improvement of what has been called the "yield characters." We may call this production breeding. On the other hand it is possible to achieve a similar effect, not by improving the "production genes" themselves, but by avoiding yield losses; by removing, or reducing, the effect of some factor which limits yield. One may call this resistance breeding. In practice the two can scarcely be separated; but they receive a different emphasis in every breeding scheme.

It is obvious that, from the viewpoint of utilising resources of soil fertility, manpower, machinery, etc., the second kind of approach is the more valuable. A crop which suffers damage will often require little less of soil resources and human effort than one which remains intact, the more so the later in the life cycle the damage occurs. A crop ruined in the seedling stage can often be replaced at relatively slight cost ; but a mature crop which sheds its grain, or a plantation a generation old destroyed by parasites, is a more serious loss. "Production breeding" as a rule demands an additional investment, in particular in plant foods; "resistance breeding" insures the safety of an investment which has already been made. In the first case there is a recurrent debit item to the cost account, in the second there is not.

These observations illustrate a fact which, I believe, should be foremost in our minds when we consider plant breeding as a major factor in the utilisation of land resources: that there are policy considerations which transcend the temporary economic or national interests of the day. There are others. We must consider the claims of projects to improve long-lived crops, such as forest trees, where the benefit will accrue to future generations; or of long-range projects of distant and uncertain promise. Looking at the world at large, we must consider whether the scientific resources, at a time of acute shortage of trained and experienced workers, are best employed where they are or whether some of them should be re-deployed in countries where plant breeding as yet finds wide empty spaces. But 
first we must pass in brief review the main problems of, and techniques for, breeding and maintaining high-yielding crop plants.

\section{BUILDING STONES}

The first stage in any breeding project is the choice of the material in which to select. Now that in many countries the old adapted "land races" have been replaced by selections, our breeding material is built up from various sources, and often the best of these are far afield. On the choice of these building stones depends the nature and range of variation. It is therefore essential that a wide range of the existing variation in any one crop plant should be available if the best choice is to be made. Breeding aims and methods alter, and hence it is highly desirable that all genic resources should be preserved for future generations. Our very efforts of producing high-yielding strains have the effect of reducing the variability of a species. This has already caused apprehension to maize workers after only a quarter of a century of intensive inbreeding.

To be of real value to the plant breeder, such collections must be observed, described and classified; otherwise they are scarcely more useful to him than are museums or herbaria.

The first man clearly to conceive these ideas, with a rare breadth of vision, and to carry them into effect on a truly stupendous scale, was N. I. Vavilov. ${ }^{33,7}$ His work, though now submerged, still serves as an inspiration. His explorations and systematic observations led him to the discovery of the "centres of development," areas where cultivated plants originated and evolved and where now the greatest density of variation is to be found. These centres yielded to him not only essential knowledge, but equally essential plant material, which he brought back to the Soviet Union, and with a vast team of collaborators, grew, observed and described in a number of stations under carefully selected ecological conditions. Thus he provided the plant breeder with a great range of the world's variation, and made it accessible by devising a system of description and classification.

Outside the Soviet Union, perhaps the most successful enterprise in this field is the Commonwealth Potato Collection at Cambridge. ${ }^{19}$ It is to be hoped that work on this great collection will be carried to its logical conclusions by developing research activities in genetics, cytology and allied fields for which it affords such unique opportunities.

An important move is the recent proposal of the Food and Agriculture Organisation of the United Nations to set up a classified catalogue of cultivated plants. All participating countries will maintain, and make available to others, all varieties which are cultivated in their area, and also breeders' lines which may be of particular interest and usefulness to breeders in other countries. Descriptions of all varieties in their national collections will be sent to F.A.O. where they will be classified and made available to breeders 
all over the world. Immediate prospects are catalogues for wheat and rice, but other self-fertilised, and ultimately the cross-fertilised plants, are to follow. This scheme has many advantages. It maintains all types in their own habitats, it stimulates local,interest, it is relatively inexpensive.

Its shortcomings are noted in the F.A.O. report, and it is to be hoped that they will be remedied in time. The most relevant one is that it makes no provision for the collection and classification in non-participating and especially in primitive countries, in fact, in some of those with the greatest wealth of plant types, which are still awaiting full exploration by collecting expeditions. So far the scheme fails to provide, or to offer assistance, for the establishment of world collections, with the excellent opportunity these afford for observation and research. But these gaps are mostly not final and should not detract from the real advance this scheme represents. It may be hoped that its extension to other crops will be rapid. Once it is under way much of the world's gene resources will, for the first time, be available to the whole world.

\section{VARIATION AND SELECTION}

In endeavouring to produce superior varieties from combinations of existing ones, the aim is either to combine one character (e.g. winterhardiness) contributed by one parent, with another character (e.g. high yield) contributed by the other parent. Or else it may be intended to exceed the level of both parents with regard to one character such as high yield. We must now consider the variation and response to selection of the characters which determine yield.

We have already recognised the distinction between resistance and production characters. But there are further distinctions which are of relevance for an understanding of variation and selection. Some yield characters are determined by few genes with marked effects, others by a number of genes with weak individual effects ${ }^{29}$; Mather $^{8,25}$ called the former major or oligogenes, the latter polygenes. Oligogenic characters often are not strongly influenced in their expression by the environment, they are observable even in single plants or at any rate in small families. Polygenic characters, on the other hand, are more subject to environmental variation so that their action often cannot be reliably ascertained in single plants or their immediate progenies ; they are, relatively, non-observable. ${ }^{10}$ These three kinds of distinction are not unrelated and fig. I illustrates the general trends of the relationships.

Resistance characters are either oligogenic (examples are stem rust and bunt in wheat, crown rust and smut in oats, wilt in flax, blight, wart and virus $\mathrm{X}$ in potatoes, mildew in lettuce, smudge in onions), or polygenic (e.g. winterhardiness, drought, lodging or shedding in wheat, woolly aphis in apples). ${ }^{6,20}$ More often than not 
they are observable, or can be made so by modifying the environment : we infect with pathogens, use freezing chambers or drought machines ; we apply heavy fertiliser dressings to induce lodging, we seek out specific environments for comparative tests.

When the number of genes determining resistance or immunity is small, then the backcross technique, so effectively used by Briggs and his co-workers ${ }^{20}$ in introducing resistance to bunt into Californian wheat, can be applied to great advantage. This allows the transfer of essential genes, accompanied by a minimum of the genotype of one variety, into that of another, with relatively little effort, yet with great precision. This method, which could be applied more widely than has been the case, has the great advantage of avoiding as far as is

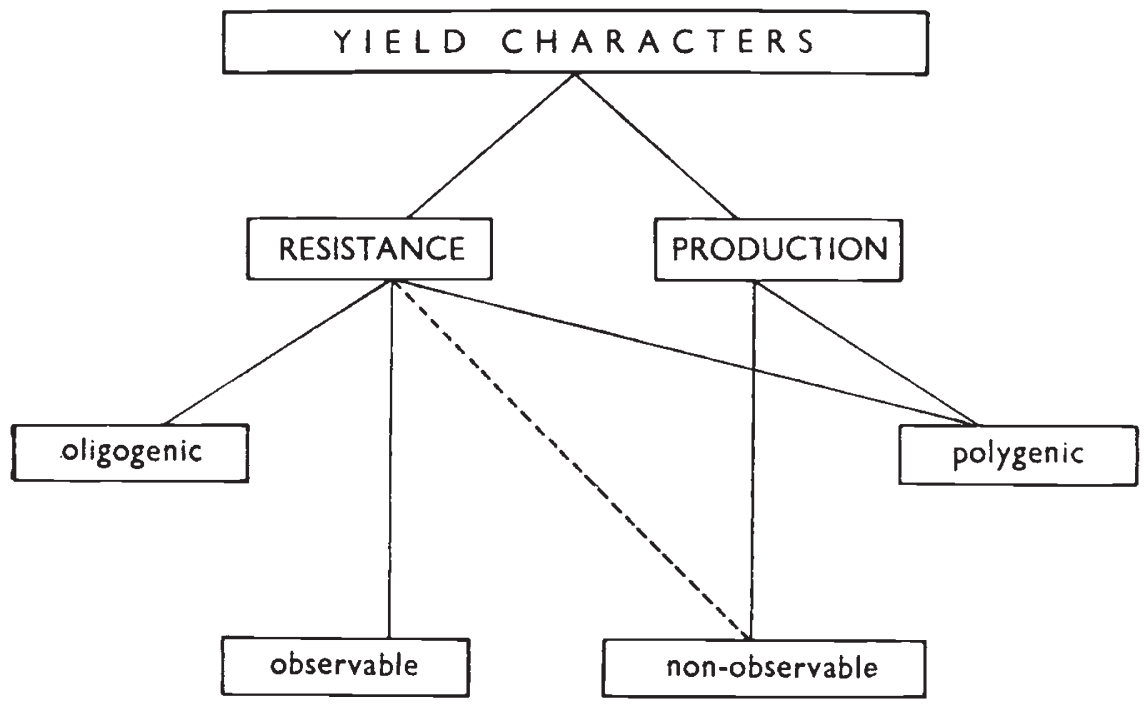

Fig. 1.-Classification of yield characters. Full lines indicate common, broken lines less common relationships.

possible the need for dealing with polygenic differences in characters other than those which are the object of resistance breeding. In other types of mating, however, this factor may impair the effect on yield which has been attained through improvement in the resistance character itself. So we see that problems of selection for polygenic characters enter into most projects of breeding for yield, though to a varying degree.

Production characters nearly always are both polygenic and non-observable. This means that breeding for such characters, as compared with resistance ones, encounters special obstacles. Genetic theory shows that the frequency with which any gene combination occurs is inversely proportional to the gene number. Hence combinations of numerous alleles can be expected only in large populations; but if the character cannot be reliably recognised in single plants or their immediate progenies, elaborate tests are required, 
the effort and expense of which reduce the size of the population to which they can be applied. So we find that, where large numbers are needed most, we can afford them least. Thus, in polygenic characters which are not observable in single plants, we are confronted with the paradox that small progress is easier to obtain, but great progress is easier to find. ${ }^{10}$

From this general analysis we conclude that the surest approach is the breeding for resistance characters which are-or can be madeobservable. We have already seen that to remove the limitations to yield is sounder, from the viewpoint of conservation and utilisation of resources, than is the breeding for production characters proper; we now find that on the whole it is also easier. Yet progress in the latter field is both important and promising; such as is on recorde.g. increased sugar yield in sugar beet-has been achieved by using large populations over long periods of selection. This approach, as we have seen, has its limitations; and these have become apparent among others in the example quoted. Further progress will largely depend on our understanding of the inheritance and of the nature of yield characters. This has been strikingly demonstrated in the utilisation of hybrid vigour.

The achievements of this method $2,20,34$ - the yield increase in maize for which it is responsible has already been mentioned-are too well known to require more than a brief reference. Self-fertilised plants are usually homozygous, hence have a polygenic system with an internal balance ; but cross-fertilised plants receive their chromosome sets from two different parents, hence have a balance which is relationally selected. ${ }^{25}$ In these plants we select individuals not so much for their own performance as for their combining ability. We select, in fact, combinations. These are unstable and have to be constantly reproduced. But, in the breeding of asexually propagated plants, segregation can be prevented and heterotic effects can be permanently retained by the interruption of sexual propagation. By evading segregation, we evade the restrictions on gene combination which linkage imposes, and by avoiding homozygosity we avoid the effects of harmful mutants. This method is most easily applied where fertilisation can be readily controlled (e.g. maize, tomatoes, pine trees) or where special controls can be introduced, such as plasmatically inherited male sterility (e.g. onion, sugar beet). But the potentialities of hybrid vigour are not nearly exhausted nor even fully explored ( $c f$. p. 96) ; moreover it is a potent element in the yield increases of "polycrosses" and other " synthetic varieties" (cf. p. 98).

Recently Harland $\mathbf{1 8}$ reported on a system of repetitive selection for combining ability without previous inbreeding which he found successful in maize breeding in Peru. He proposes it as a rapid and inexpensive method for underdeveloped countries, for crops of secondary importance, or for slow-growing plants such as forest trees, coconuts, and possibly cocoa and rubber. 
Other approaches for increasing the efficiency of breeding for yield have been used in recent years. The choice of parent material more often than not is empirical, so that an indication of the prospects of a cross, prior to selection, is of great advantage. Harlan et al. ${ }^{16}$ found that the yields of unselected hybrid populations in $F_{8}$ served this purpose, and Immer ${ }^{22}$ obtained similar results in $\mathrm{F}_{2}$ or $\mathrm{F}_{3}$.

Natural selection has been used to increase the frequency of adapted variants, both in hybrid bulks of self-fertilised plants and in populations of cross-fertilised ones. This has been done systematically in the branches of the Swedish Seed Association, but in few other places. In small countries, or for special problems, international co-operation may be called for. For example, the spreading of the combine-harvester in Western Europe has sharply accentuated the need for wheats resistant to shedding of grain. Since winds cannot be relied upon to occur each year and "synthetic" testing devices are rarely adequate, hybrid bulks-and again final observational tests - might be grown in a windy country with otherwise similar climatic conditions, such as New Zealand, the main selection being done in Europe.

Statistical methods for yield tests of large numbers have been recently devised by Yates ${ }^{35,36}$ and developed by Goulden and others. ${ }^{12,13}$ In some circumstances they have substantially increased the efficiency of tests. Much would be gained if we understood better the physiology of the interactions of heredity and environment which we are now able to measure more accurately.

Ultimately the best chance of progress comes from greater knowledge of the inheritance of yield characters and of the nature of the characters themselves. We know little of the organisation of polygenes in plants with different breeding systems, and of the progress of selection in various systems of breeding and selection. A searching enquiry into methods of selection in sugar beet is in progress at Hilleshög in Sweden, and problems of selection in wheat and other self-fertilised crops are under investigation in a number of countries, including New Zealand.

Similarly, breeding for yield would be greatly advanced by a fuller understanding of the nature of the yield characters. The breeder has received help from the plant pathologist, the analytical chemist and a variety of technologists. But an understanding of the nature and the workings of the characters we are breeding foras distinct from their effects-still eludes us. Plant breeding institutions are by now accustomed to geneticists, pathologists, statisticians and cytologists; is it not time they opened their doors more widely to the physiologist and the biochemist?

\section{NEW GENES}

After more than twenty years' research it appears that induced mutation is a destructive rather than a constructive change. As 
Darlington and Mather point out (p. 327), "the changes which are constructive in the sense of being new adaptations are of polygenic origin" ; " the overwhelming majority of mutants in Drosophila and Antirrhinum, especially those produced by X-rays, are hypomorphic and selectively negative, or at best selectively neutral." 8

Well authenticated cases of useful induced mutants in crop plants and especially of mutants with increased yield, are few indeed. Gustafsson's ${ }^{1,15}$ extensive work, especially in barley, has shown that useful variants with specific characters (stiffness of straw, earliness) could be induced. The frequency of stiff-strawed mutants was $0 \cdot 2$ per cent., and one-quarter of them gave yields similar to those of the mother strain. The yield increases reported by Gustafsson are small and therefore difficult to prove.

Similar types of induced mutants have been found by Swedish and other workers in some other crop plants. It seems that X-ray (or mustard gas) induced mutability is not without promise where a specific genetic change is controlled by a change-presumably a destructive one-in a small sector of a chromosome. If this is correct, its application to plant breeding is restricted, though by no means altogether unpromising. Whether the heterotic effect of certain X-ray-induced lethal mutants could be utilised remains to be seen. ${ }^{14}$ Lewis ${ }^{23}$ suggests possibilities such as the production of dwarf and precocious root-stocks in cherries and pears and of self-compatible mutants, which he was able to produce in Oenothera organensis.

\section{CHROMOSOME DOUBLING}

The effect of chromosome doubling-without crossing-has been applied to plants with a variety of breeding systems. In barley, a self-fertilised plant, Gustafsson, ${ }^{1}$ after intercrossing many tetraploid barley strains, has not got much beyond 80 per cent. of the yield of the original diploid. Among cross-fertilised plants, however, tetraploid rye and red clover ${ }^{\mathbf{1}}$ are distinctly promising, as is the partially triploid strain produced by Rasmusson in sugar beet. Here the tetraploid can be propagated from seed but is less productive than the diploid; the hybrid of tetraploid and diploid produces a mixture of vigorous triploid, normal diploid and inferior tetraploid, with a composite return in excess of the diploid. In sexually propagated plants there probably is a wide field for autoploidy, the more so if the original diploid is highly heterozygous. A recent example is the tetraploid pear Fertility which has larger fruits than the diploid. ${ }^{5}$

\section{SPECIES COMBINATION}

The potentialities of specific and generic combinations have as yet to be fully exploited. Here there is time and need for only a few general remarks. "Wide" crosses have been made for the purpose of transferring to a cultivated species some desirable character 
from a related wild or cultivated species or genus. Where there is a degree of chromosome homology, the problems of variation and selection are akin to those we have encountered in crosses within species; yet the difficulties are magnified. Where the inheritance of the desirable character and the breeding system permit a short-cut, such as recurrent backcrossing, the process is relatively simple. This is the case in the successful transference of resistance to blight and to virus $\mathrm{X}$ from Solanum demissum to our cultivated potato. In many species crosses, sterility or low crossing-over severely restrict the frequency of the desired combinations. This can be met by selecting in very large populations. Baur's ${ }^{6}$ attempt to transfer resistance to the vine louse and mildew from the American Vitis rupestris to the European Vitis vinifera, was made with a material amounting to millions of seedlings; the transfer of resistance characters from other members of the tribe Triticine-the wheat family-to our common wheat, meets sterility barriers which have been overcome only in a few instances (e.g. resistance to stem rust from durum and emmer wheats). McFadden and Sears ${ }^{24}$ recently reported an ingenious approach which appears to have great possibilities. They construct, by crossing and chromosome doubling, new species combinations containing those species from which characters are to be transferred. The new combinations, having the same chromosome number as our bread wheat, are more readily crossed with it than are the species themselves.

Species combination by crossing and chromosome doubling may be an end in itself; it results in the creation of a type with the character of a new species. While this method promises a good deal, as yet it has made no major contribution to the world's resources. Perhaps the most promising combination is the wheat-rye hybrid produced by Müntzing ${ }^{1}$ at Svalöf. However, such new types are more or less uniform. Variability has to be created, just like the species itself, for without variation there is no adaptability. This can be obtained by repeating the process with various types, by further species crosses, or both. This vast effort invites co-operation; but so does also the exploitation of wide crosses. As a rule we reject in one environment what would be selected in another. On our own, we produce limited numbers of a few combinations in a restricted environment, wasting most of the proceeds ; in co-operation, we can multiply the material, widen the conditions of selection, and utilise the material to the full.

\section{POPULATION PROBLEMS. MAINTENANCE OF VARIETIES}

From the early days of plant breeding, uniformity has been sought after with great determination. For this there are many reasonstechnical, commercial, historical, psychological, æsthetic. It seems to me that the "purity concept" has not only been carried to 
unnecessary lengths, but that it may be altogether inimical to the attainment of highest production.

This concept originated in the breeding of the self-fertilised cereals where high standards of homogeneity are readily attainable. But even here the extreme of purity, required by the seed regulations of various countries, is neither in itself a pre-requisite of high yield, nor is it, in fact, attainable. We know that the mutation rate is much higher than breeders often realise, and that the majority of the mutants are not distinguishable except by elaborate tests. I have maintained for years a strain of common wheat with one chromosome arm duplicated ; 11 no doubt this must have physiological effectsbut it has no visible ones. "Purity" is concerned with characters which are readily seen but often are of little significance. Its excessive pursuit absorbs energies, delays progress, and deludes the breeder and the farmer as to the real merits of crop varieties. I suspect that often it is little more than a commercial convenience.

In the cross-fertilised plants, where highest purity standards are unattainable, we don't worry about it to the same extent, and no doubt this is right. We have seen that the most successful method of raising yields - the breeding for heterotic effects-succeeds through inducing the maximum of internal heterogeneity, and that internal homogeneity as a rule causes depression. "Polycrosses" 32 and other types of "synthetic varieties," such as the line mixture used by Harland ${ }^{17}$ in cotton, achieve internal heterogeneity with simple means. But this is probably not the sole reason for their higher yields. These varieties, being biological mixtures, are genetically fluid hence they are open to improvement by selection or partial replacement; and, being heterogeneous, they are likely to be more adaptable to variations in the environment than are rigidly uniform races. From this follows that line mixtures should give higher yields than simple pure lines, even in the self-fertilised crops, and in fact this has been found in some instances but not in others. ${ }^{9}$

In the cross-fertilised plants the maintenance of improved varieties is mainly concerned with retaining any heterotic effects and with excluding undesirable outcrossing, both of which are aided by reducing as far as possible the period of propagation. Yet even in this fluid material, certification systems, and price differentials, often bear little relation to the relative productivity of successive stages of multiplication, but are mainly designed with a view to administrative and commercial convenience. This is a statement of fact but not an implied criticism; for an orderly maintenance and distribution of selected stocks is not possible without a more or less rigid system. It should be sufficiently flexible, however, to ensure a rapid distribution of superior stocks to the largest possible number of users. This cannot be achieved unless the price is within the reach of every grower.

Freedom from disease is a principal aim of varietal maintenance in all crop plants ; but this is especially so in the asexually propagated 
plants which normally lack the purification through a generative phase. In such crops as potatoes, "seed" stocks are raised in areas where the carrier of virus diseases is absent, the basic nucleus being maintained in insect-proof greenhouses. One may have to go farther afield for disease-free stock : virus-free "Lloyd George" raspberries are now being sent from New Zealand to Britain. Here we find another field for international co-operation.

\section{UNDERDEVELOPED CROPS : UNDERDEVELOPED COUNTRIES}

In the first section of this paper I said that plant breeding had made its mark in every part of the globe. Yet, even in countries with a long tradition of plant improvement, there are crops in which nature alone has shaped heredity. Most prominent among these-though not the only ones-are the forest trees. In a report on its post-war plans ${ }^{21}$ the Forestry Commission of Great Britain has a single reference to forest tree breeding: "Other lines of research which may be mentioned are tree breeding and vegetative reproduction;" . . . It is not considered that either of these two lines of research is sufficiently urgent to justify taking them up as major projects after the war." In many other countries tree breeding is not even mentioned in official reports-and this, incidentally, applies also to the programme of the Forestry Session of the present Conference. Yet, wherever it has been attacked with knowledge and vigourmainly in Sweden, Denmark, Germany, U.S.A., Russia, South Africa and Canada ${ }^{27}, 31$-it shows excellent promise of large advances in yield. All the techniques we have passed in review-selection, hybrid vigour, chromosome doubling, species crosses-have been used in a variety of genera. New and old methods have been applied for speeding up flowering, fruiting and testing, with the result that breeding, especially of the shorter-lived tree types, is now relatively rapid and inexpensive. ${ }^{28}$ Yet even were this not so, posterity has a claim to our attention.*

Some of the tropical crops have suffered similar neglect. What can be achieved is demonstrated by the great progress in crops such as sugar cane and cotton. In others much remains to be done. This applies particularly to newly-opened-up territories where new crops are introduced. It is to be hoped that schemes such as the British Food Corporation's East African Groundnut Scheme will have a team of experienced plant breeders among its research workers.

In some of the oldest countries, and crops, the position is not dissimilar. I have often wondered whether the many wheats from

\footnotetext{
* In the report of the Commission of Enquiry into the Swollen Shoot Disease of Cocoa in the Gold Coast (H.M. Stationery Office, Colonial No. 236, Iondon, 1948), the commission finds "the development of varieties resistant to infection would be an ideal solution of the problem " but asserts that " it will be agreed that this is a long-term problem without any immediate practical significance." I, for one, cannot agree. Obviously the ideal solution of a problem which is vital to the existence of the cocoa industry is of immediate practical significance; and a long term is not reduced by delay.
} 
China which are more prone than any others to shed their grain, suffer severely in their own habitat; that this is so is confirmed by Chang. ${ }^{20}$ Even a slight improvement in the yielding capacity of rice in India or China-and the opportunities are said to be excellent ${ }^{26}$ -would have profound effects on the nutritional standards of vast populations.

Problems such as these open wide vistas of fields in which plant breeding has as yet to make its major contribution to the resources of mankind. One sometimes feels that they dwarf the tasks on which many of us are now engaged.

\section{SUMMARY}

I. Plant breeding has enormously increased the world's resources by an effort and expenditure for research and for introduction into industry infinitesimal in relation to the benefits.

2. It aims at optimal adaptation of the plant to the environmentecological, economic, social ; any change (climate, fertility, management, parasites, techniques, utilisation, tastes) demands adjustment of heredity. There can be no efficient land utilisation without efficient plant breeding.

3. Collection, survey and conservation of the world's gene resources are essential for providing breeding material for ourselves and further generations. The FAO plant catalogue should be supported, expedited and developed.

4. Breeding for resistance to factors limiting yield is usually more profitable than breeding for increased production proper ; it is easier (fewer genes, easier to observe and to test) and, with a view to resource utilisation, more economical.

5. Progress is facilitated by studies of inheritance, selection, the nature of characters - calling for co-operation of geneticists, physiologists, biochemists, pathologists, statisticians. Genetic research has yielded heterosis and backcross methods.

6. Application of induced mutation is probably limited. Chromosome doubling is promising in some cross-fertilised and asexually propagated plants.

7. Potentialities of species crosses - without and with chromosome doubling - are yet to be exploited. Resistance characters have been transferred. "Species construction" requires long-range effort, is of uncertain outcome but of ultimate promise.

8. Varietal purity can be exaggerated, it may be harmful. In cross-fertilised plants " synthetic varieties" are superior to pure stocks. Administrative and commercial considerations should be harmonised with those of production.

9. International co-operation is needed for assembling and maintaining plant collections, harnessing natural selection, organising and exploiting long-range projects, exchanging material, information and personnel. 
Io. Breeding of crops so far relatively neglected (especially forest trees and tropical crops), and in new or scientifically underdeveloped countries, promises a great contribution to the world's resources. Considering the world-wide shortage of trained and experienced workers, this suggests a measure of re-deployment of scientific resources.

\section{REFERENCES}

1 AKerman, A., TEDin, O., ANd FröIER, K. 1948. Svalof, ז886-1946. Lund, Carl Bloms Boktryckery, pp. $3^{89}$.

2 AShton, T. I 946 .

The Use of Heterosis in Production of Agricultural and Horticultural Crops. Imp. Bur. Plant Breed. and Genetics.

3 BAYLES, B. B. 1947.

Yearb. U.S. Dept. Agric., 1943-47, pp. 379-384.

4 CRAIGIE, J. H. I 944.

Sci. Agric., 25, 5 I-64.

5 GRANe, M. B., AND thomas, P. T. 1939.

7. Genet., 37, 287-299.

- CRANe, M. B., AND lawrence, W. J. c. I 947.

The Genetics of Garden Plants. $\quad 3^{\text {rd ed. }}$ London, Allen \& Unwin. pp. 299.

$?$ Darlington, C. D., AND JANAKI, E. L. I 945.

Chromosome Atlas of Cultivated Plants. London, Allen \& Unwin. pp. 397.

8 DARLington, C. D., AND MATHER, K. I 949.

Elements of Genetics. London, Allen \& Unwin. pp. 446.

9 FRANKEL, O. H. 1939.

7. Agric. Sci., 29, 249-261.

10 FRANKel, O. H. 1946.

Heredity, $I$, IO9-I 20.

11 FRANKEL, O. H. 1949.

Heredity, 3, 163-194.

12 GOULDEN, C. H. 1937.

Can. Dept. Agric. Techn. Bull., g.

13 GOULDEN, C. H. 1939.

Theory and Methods of Statistical Analysis. New York, Jon Wiley \& Sons.

14 GUSTAFsSON, A. I946.

Hereditas, 32, 263-286.

15 GUSTAFSSON, A. 1947.

Hereditas, 33, I-100.

16 HARLAN, H. V., MARTiNI, M. L., AND STEVENS, H. 1940.

U.S. Dept. Agric. Techn. Bull., 720.

17 HARLAND, S. C. 1944.

Inst. Cotton Genetics, Lima, Peru, Bull. I.

18 HARLAND, s. C. 1946.

Trop. Agric., 23, I 14. 
19 HAWKES, J. G. I94I, 1944.

Potato Collecting Expeditions in Mexico and South America, 194I-44. Imp. Agric. Bureaux.

20 HAYES, H. K., AND IMMER, F. R. 1942.

Methods of Plant Breeding. New York and London, McGraw Hill. pp. 432.

21 H.M. FORESTRY COMMISSION. 1943.

Post War Forest Policy. London, H.M.S.O. p. 69, paragraph 395.

22 IMMER, F. R. 1941.

7. Amer. Soc. Agron., 33, 200-206.

23 LEWIS, D. 1946.

Nature, $158,519$.

24 MCFADDEN, E. S., AND SEARS, E. R. 1947.

7. Amer. Soc. Agron., 39, $1011-1026$.

25 MATHER, K. 1943.

Biol. Rev., $18,32-64$.

26 QUISENBERRY, K. S. 1948.

Chron. Bot., II, 237-245.

27 RICHENS, R. H. 1945.

Forest Tree Breeding and Genetics. Imp. Agric. Bur. Joint Publ. 8.

28 RIGHTER, F. I. 1946.

Science, 104, $1-3$.

29 SMITH, H. H. 1944 .

Bot. Rev., Io, 461-482.

so STADLER, L. J. 1947.

Econ. Bot., I, 5-19.

81 STOCKWELL, P., AND RightER, F. I. 1947.

Yearb. U.S. Dept. Agric., 1943-47. pp. 465-472.

82 TYSDAL, H. M., AND GRANDALL, B. H. 1948.

7. Amer. Soc. Agron., 40, 293-306.

33 vavilov, N. I. 1935.

Theoretical Bases of Plant Breeding. Moscow.

84 WHALEy, W. G. 1944.

Bot. Rev., IO, 46I-498.

85 YATES, F. 1936.

7. Agric. Sci., 26, 424-455.

86 YATES, F. $193^{8}$.

J.R.S.S., 5, 70-74. 